\title{
A unique method for management of benign colonic masses: case report
}

\author{
Anushtup De ${ }^{1}$, Bhaskar Nandi², Jaspreet Singh Bajwa ${ }^{1 *}$, Rajesh K. Singh ${ }^{3}$, Deepika Parwan ${ }^{4}$, \\ Poonam Dager ${ }^{1}$, Chandraketu Solanki ${ }^{1}$
}

\begin{abstract}
${ }^{1}$ Department of General and Laparoscopic Surgery, ${ }^{2}$ Gastroenterology and Hepatobiliary Sciences, ${ }^{3}$ Department of Anaesthesia, ${ }^{4}$ Department of Pathology, Sarvodaya Hospital, Faridabad, Haryana, India
\end{abstract}

Received: 09 November 2021

Accepted: 01 December 2021

\section{*Correspondence:}

Dr. Jaspreet Singh Bajwa,

E-mail: jpsbajwa25@gmail.com

Copyright: ( ) the author(s), publisher and licensee Medip Academy. This is an open-access article distributed under the terms of the Creative Commons Attribution Non-Commercial License, which permits unrestricted non-commercial use, distribution, and reproduction in any medium, provided the original work is properly cited.

\begin{abstract}
Even though lipomas are most common non-epithelial tumors of the large intestine, they mostly present with nonspecific symptoms. Intussusception is the most common morbidity related to such lesions and may present as intestinal obstruction. We present here a case of a young female who presented to gastroenterology department as a case of pain abdomen and nausea and a provisional diagnosis of subacute intestinal obstruction was kept. Contrast enhanced CT confirmed a diagnosis of intussusception due to an ascending colon mass? likely lipoma. The colonoscopy was done and biopsy was taken which was non-specific for malignancy. Patient, after taking due consent, was taken for surgery and laparoscopic assisted submucosal excision of lipoma was done and we will discuss the same. Endoscopic excision of lipomas has been reported but when failed, mostly segmental resection of the colon has been reported. To the best of our knowledge, this is the second reported case of laparoscopic assisted colotomy with submucosal excision of an intussuscepting colonic lipoma and first one in ascending colon.
\end{abstract}

Keywords: Intussusceptions, Lipoma, Laparoscopic assisted submucosal excision, Colotomy

\section{INTRODUCTION}

Out of all digestive system, colonic lipomas are most common (64\%) and are most frequent non epithelial tumors. ${ }^{1-3}$ Overall they are more common in females and about $90 \%$ submucosal. ${ }^{1,2}$ These are rarely symptomatic, especially up to $4 \mathrm{~cm}^{4}$ When large, they mostly present as intussusception with non-specific or intermittent symptoms and hence are difficult to diagnose. 5\% incidence of bowel obstruction in adults is due to intussusceptions. In non-acute settings, colonoscopic resection preferred management whereas in symptomatic cases (intussusceptions, subacute intestinal obstruction) segmental resection has been most commonly practiced. ${ }^{6}$

\section{CASE REPORT}

A 36-year-old female with no known comorbidity presented to emergency with pain abdomen for 7 days, hematochezia for 1 day and obstipation. Previously she had intermittent episodes of colicky pain since last 2 months which relieved by over-the-counter drugs. On examination, her vitals were stable but the abdomen was tender to palpate. Her routine hematology investigations were normal. In view of hematochezia, urgent colonoscopy was performed which revealed large polypoidal lesion in hepatic flexure with thick stalk and ulcer at its base and also multiple ulcers on the mass (Figure 1). Biopsy was taken which showed non-specific inflammation with no evidence of malignancy. CEA levels were also normal.

Contrast enhanced CT was done which showed lipoma of size $5.73 \times 3.17 \times 4.41 \mathrm{~cm}$ from hepatic flexure caving into adjacent large bowel with evidence of significant thickening of colon along with ileocecal junction (Figure $2 \mathrm{~A}$ and $\mathrm{B})$.

Patient was kept on clear liquid diet for 3 days and then taken up for surgery after explaining her about frozen 
section on table and in case it comes out to be malignant, the need of right hemicolectomy. The ports were inserted as shown in Figure 3 and $\mathrm{CO}_{2}$ was insufflated to create pneumoperitoneum and some adhesions were noted along the wall (Figure 4) The right colon was mobilized from ileocecal junction to hepatic flexure along the white line of Toldt and the lesion was palpated at the junction of ascending colon and hepatic flexure with no gangrenous changes on bowel. A small muscle splitting incision was given at level of umbilicus on right side and the pathological segment was taken out. Colotomy was performed along the antimesenteric border of size $4 \mathrm{~cm}$ approximately along the taenia and mass was taken out (Figure $5 \mathrm{~A}$ and B). Submucosal dissection was done and entire mass was taken out (Figure 6) and the mucosal defect was closed with interrupted vicryl 3-0. Frozen section report was awaited which came out to be benign lipomatous lesion and then colotomy was closed in double layer (interrupted vicryl 3-0 internal and interrupted silk 3-0 seromuscular outer layer). The bowel was replaced (Figure 7) and sheath closed with PDS loop no1. Skin closed with nylon 2-0 after keeping a small suction drain subcutaneously.

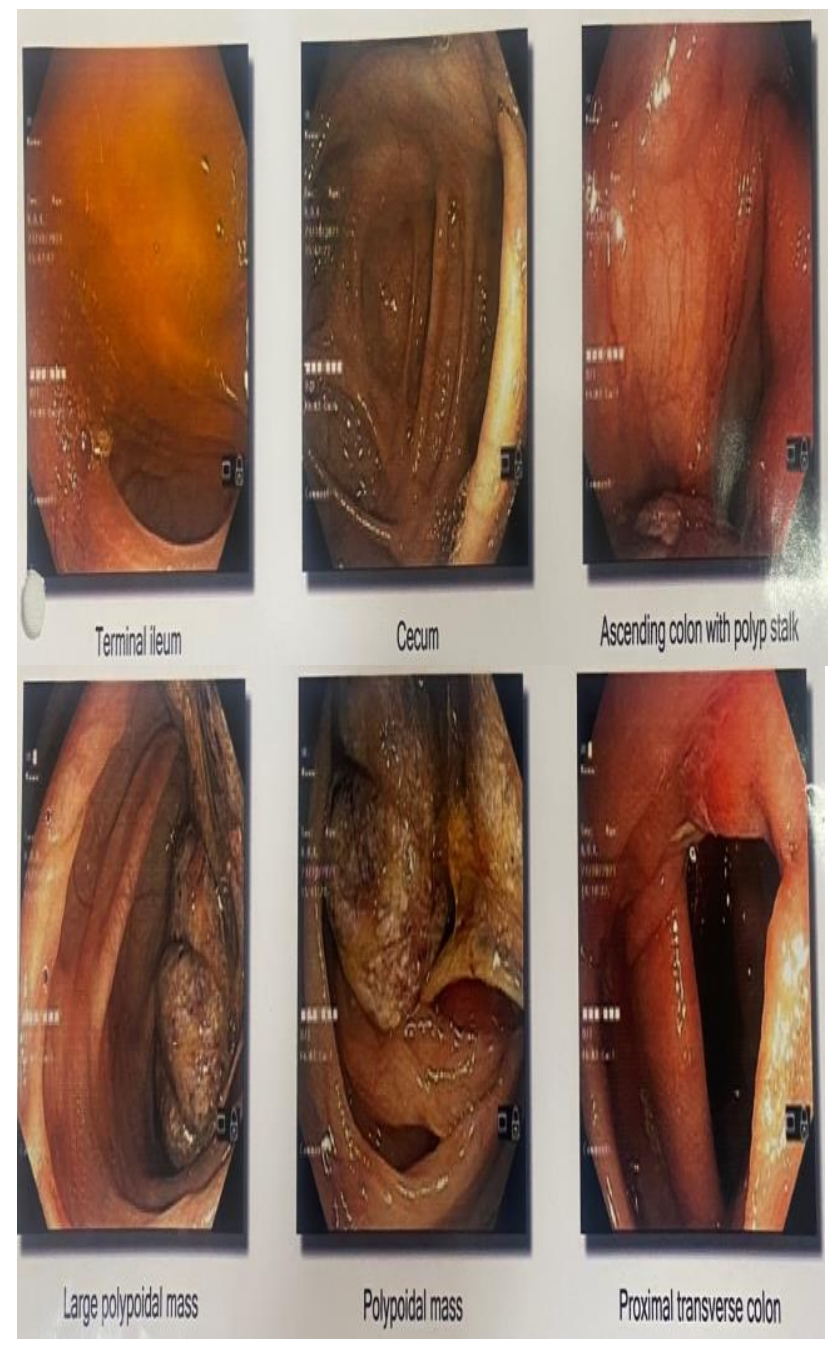

Figure 1: Colonoscopic view of large polypoidal mass in-hepatic flexure.

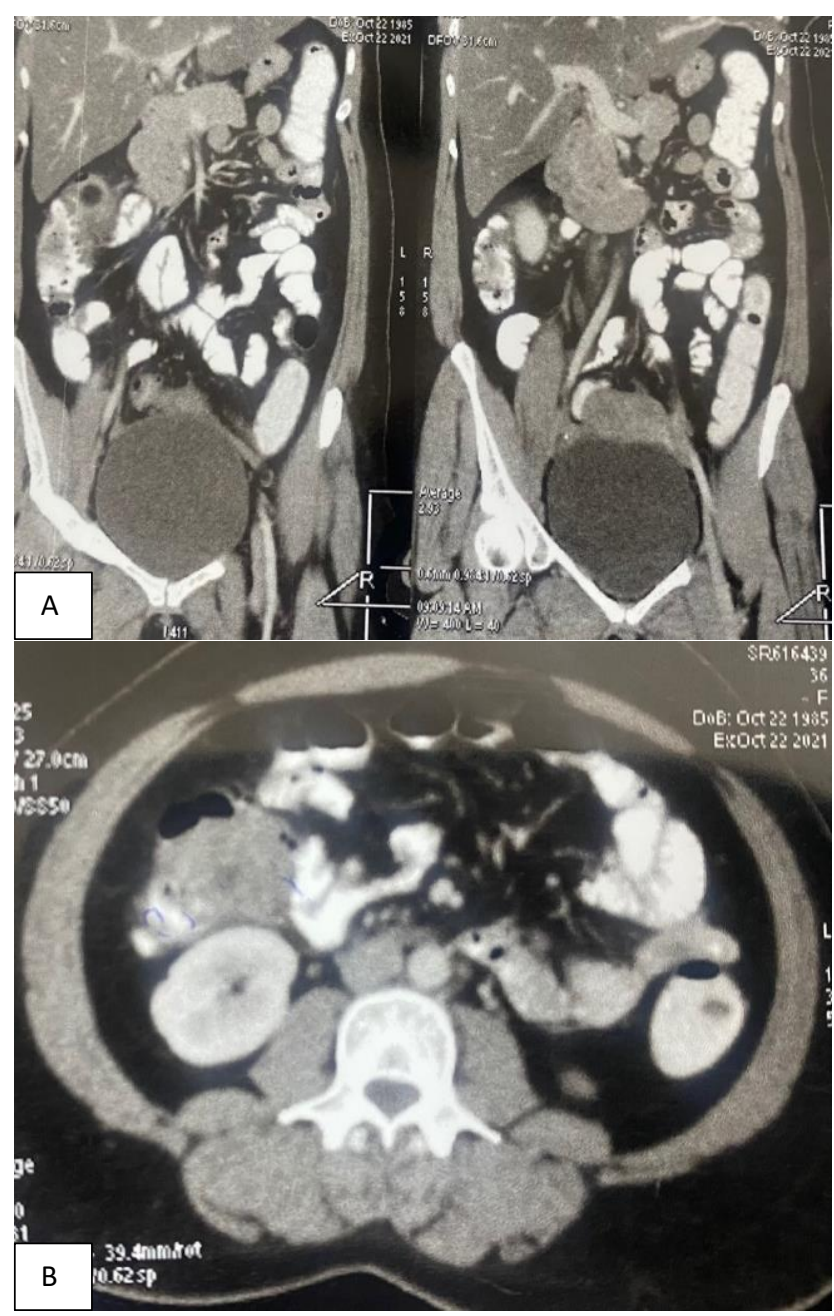

Figure 2 (A and B): Coronal section CT of colonic mass just below liver with intussusception and transverse section CT of target sign typical of intussusception.

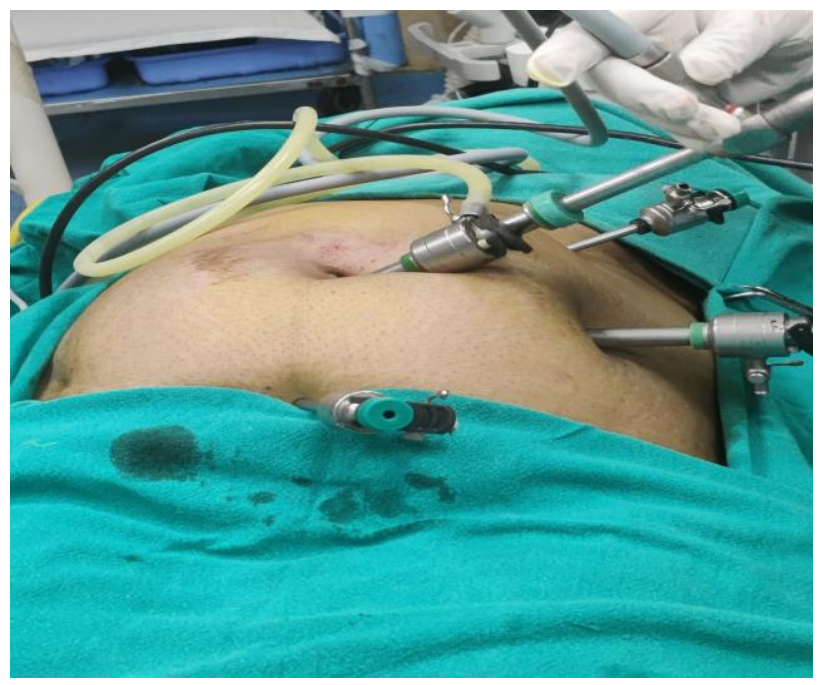

Figure 3: Port insertion with umbilical camera port $(10 \mathrm{~mm})$, paraumbilical left side $(10 \mathrm{~mm})$ and left hypochondrial $(5 \mathrm{~mm})$ surgeon ports and suprapubic assistant port $(5 \mathrm{~mm})$. 


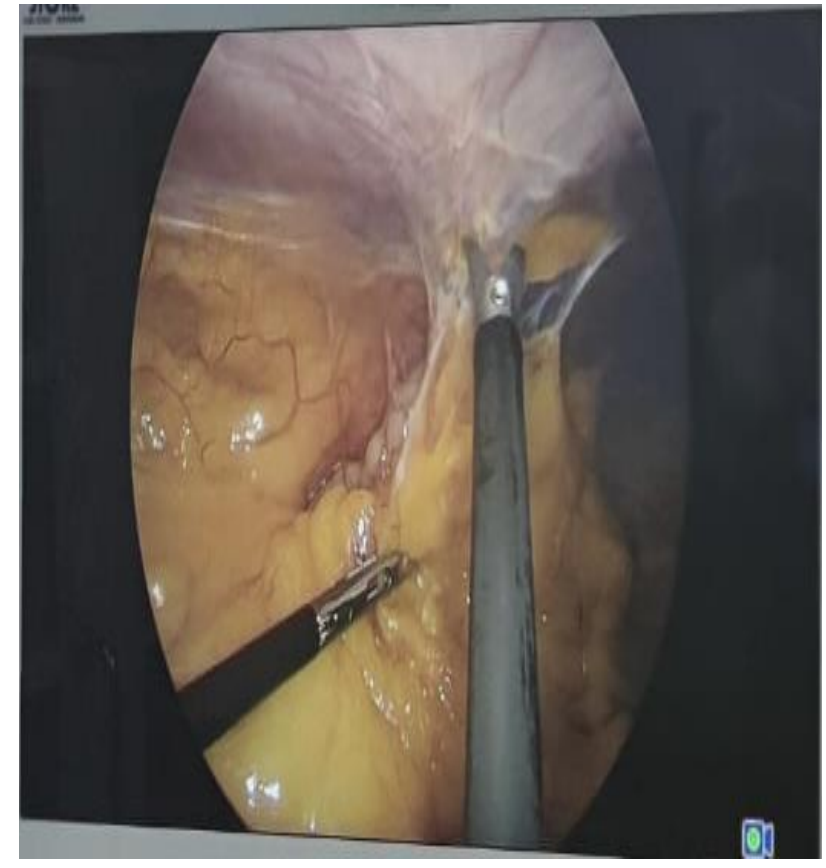

Figure 4: Adhesions found along ascending colon and anterior abdominal wall.

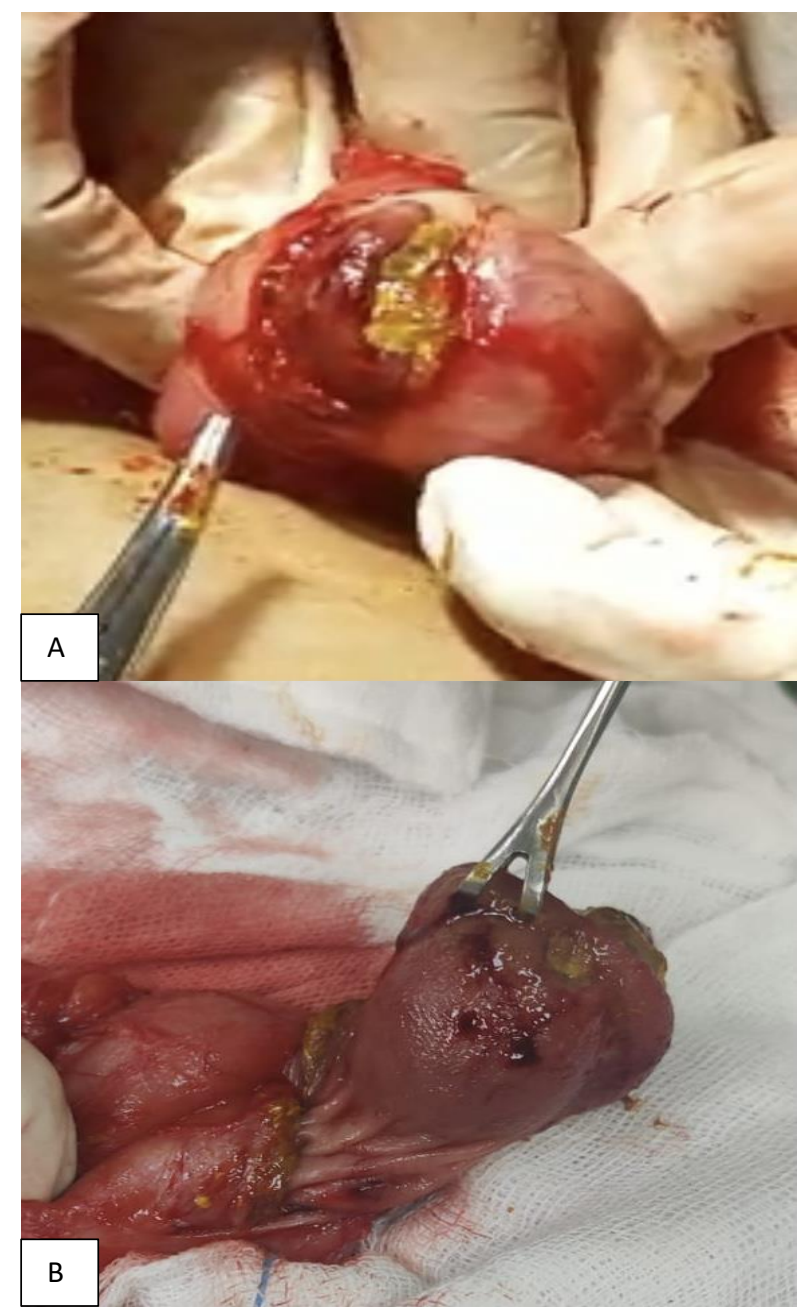

Figure 5 (A and B): Colotomy and delivered mass.

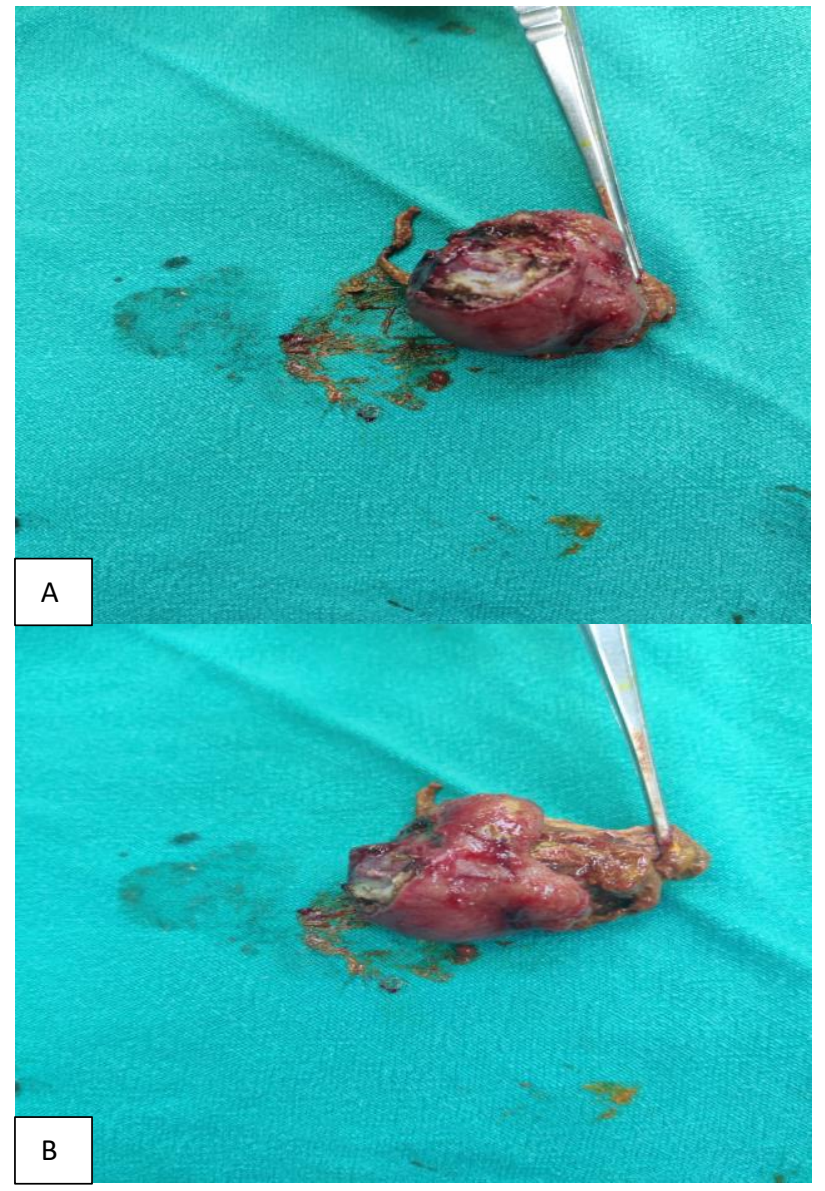

Figure 6 (A and B): Posterior and lateral view of resected specimen.

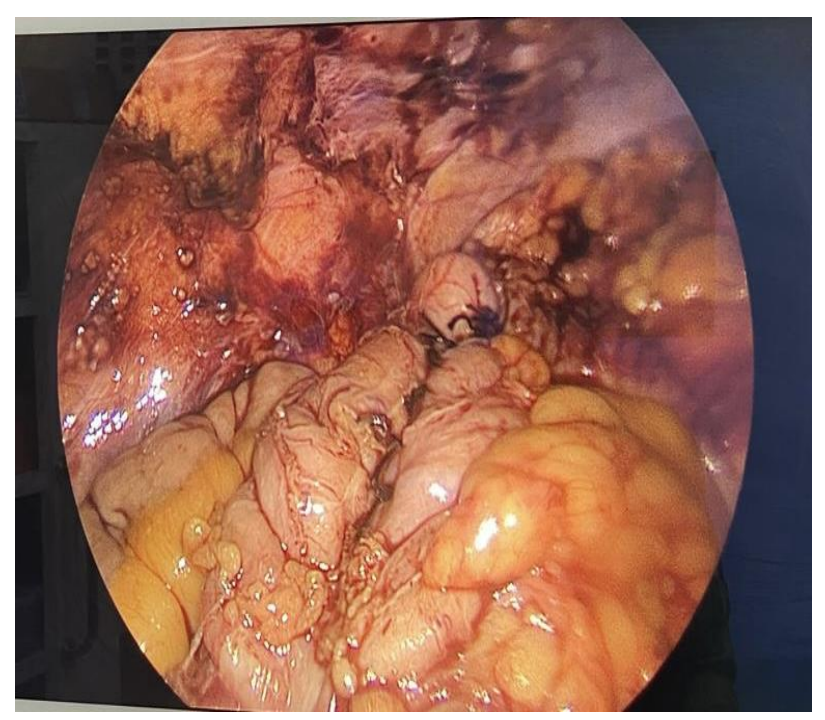

Figure 7: Laparoscopic view of closed colotomy site.

Postoperatively, the course was uneventful and patient allowed on liquids on day 3 , semisolids on day 5 and discharged on day 6. Final histology confirmed benign submucosal lipoma (Figure 8). Patient was followed till post operative day 28 and was completely asymptomatic. 


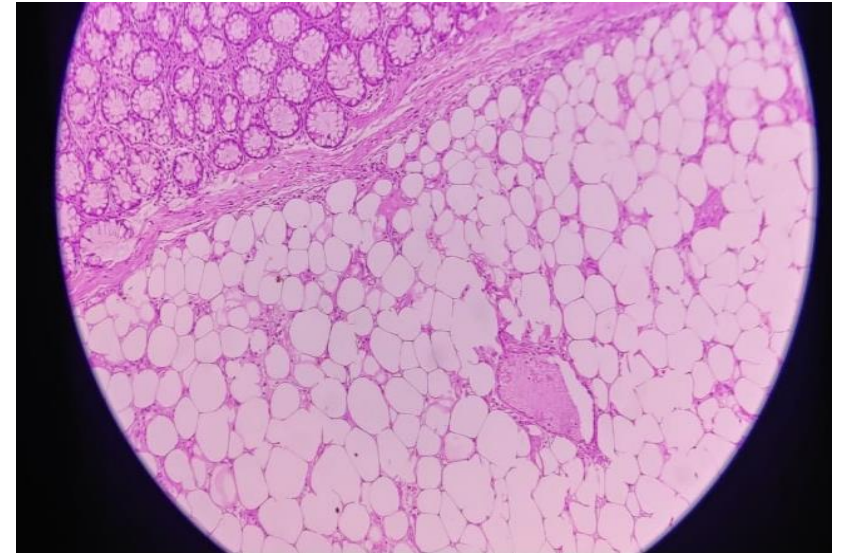

Figure 8: Final histopathology report of mucosal glands and submucosal fat lobules (well differentiated) indicating lipoma.

\section{DISCUSSION}

Colonic lipomas with frequency of $0.035-4.4 \%$ worldwide, are most commonly located in ascending colon and caecum. ${ }^{7}$ But, symptomatic colonic lipomas (i. e., intussusception) are more frequently reported in in transverse and descending colon. ${ }^{8}$ besides routine investigations, CT scan is a valuable diagnostic tool to diagnose a lipoma as these are homogenous masses with intensity of -80 to -120 Hounsfield units. ${ }^{9}$

Surgery is the treatment of choice for large symptomatic lipomas, sessile or non-suitable for endoscopic resection. In literature, hemicolectomy and segmental resection are the treatment of choice for the same. ${ }^{10,11}$ The first case reported of laparoscopic assisted colotomy guided submucosal removal of lipoma was done by Ejtehadi et al. ${ }^{1}$ The mass in that reported case was of descending colon.

Cruz et al published laparoscopic assisted endoscopic polypectomy in on 25 patients out of which 6 (24\%) had to undergo major surgeries (3 right hemicolectomy, 2 transverse colectomy and 1 left hemicolectomy). ${ }^{12} 72 \%$ were benign but all were of epithelial origin, making our case to be unique as it was of submucosal origin.

\section{CONCLUSION}

To the best of our knowledge, this is the second case over all reported to follow the technique of laparoscopic assisted colotomy guided submucosal excision of the intussuscepting benign-colonic mass and is the first one done for ascending colon/hepatic flexure mass. We strongly believe that advocating of concept of minimally invasive techniques, this method should be considered in selective patients with benign masses of colon diagnosed preoperatively to reduce the perioperative and postoperative morbidity related to colonic resections.
Funding: No funding sources Conflict of interest: None declared Ethical approval: Not required

\section{REFERENCES}

1. Farshid E, Elsamoual M, Vardhini V. Laparoscopic assisted submucosal excision of an intussuscepting colonic lipoma. J surg case rep. 2020:1-4.

2. Nallamothu G, Adler DG. Large colonic lipomas. Gastroenterol Hepatol. 2011;7:490-2.

3. Cuciureanu T, Huiban L, Chiriac S, Singeap AM, Danciu M, Mihai F et al. Ulcerated intussuscepted jejunal lipomauncommon cause of obscure gastrointestinal bleeding: a case report. World J Clin Cases. 2019;7:3765-71.

4. Crocetti D, Sapienza P, Sterpetti AV, Paliotta A, Pedulla $G$ et al. Surgery for symptomatic colon lipoma: a systematic review of the literature. Anticancer Res. 2014;34:6271-6.

5. Poling-Kempes L. Ladies of the Canyons: A League of Extraordinary Women and Their Adventures in the American Southwest. Tucson: The University of Arizona Press. 2015;viii:373.

6. Wahba M, Habib G. Endoscopic piecemeal snare resection of a Giant colonic Lipoma in a patient with intestinal obstruction. ACG Case Rep J. 2019;6:e00190.

7. Panagiotakis GI, Andreou AG, Petrakis IE, Tzardi M, Daskalogiannaki M, Chalkiadakis GE. Laparoscopic resection of a sigmoid colon lipoma in a young female patient: A case report and review of the literature. Oncol Lett. 2017;13:1303-6.

8. Mohamed M, Elghawy K, Scholten D, Wilson K, McCann M. Adult sigmoidorectal intussusception related to colonic lipoma: A rare case report with an atypical presentation. Int $\mathbf{J}$ Surg Case Rep. 2015;10:134-7.

9. Thompson WM. Imaging and findings of lipomas of the gastrointestinal tract. AJR Am J Roentgenol. 2005;184:1163-71.

10. Ghidirim G, Mishin I, Gutsu E, Gagauz I, Danch A, Russu S. Giant submucosal lipoma of the cecum: report of a case and review of literature. Rom $\mathbf{J}$ Gastroenterol. 2005; 14:393-6.

11. Jiang L, Jiang LS, Li FY, Ye H, Li N, Cheng NS et al. Giant submucosal lipoma located in the descending colon: a case report and review of the literature. World J Gastroenterol. 2007;13:5664-7.

12. Roberto AC, Rodrigo P, Madhu R. Minimally Invasive Approaches for the Management of "Difficult" Colonic Polyps. Diagnostic Therapeutic Endoscopy Vol. 2011;682793:1-5.

Cite this article as: De A, Nandi B, Bajwa JS, Singh RK, Parwan D, Dager P et al. A unique method for management of benign colonic masses: case report. Int Surg J 2022;9:217-20. 